\title{
Erratum to: Short-Segment Coil Embolization Using a Double- Balloon Technique in an Experimental Vascular Model
}

\author{
Daisuke Yunaiyama ${ }^{1}$ (D) Toru Saguchi ${ }^{1} \cdot$ Tomohisa Moriya $^{1} \cdot$ Natsuhiko Shirota $^{1}$. \\ Jun Otaka $^{1}$ - Koichi Tokuuye ${ }^{1}$ - Yuichi Nagakawa ${ }^{2}$ Akihiko Tsuchida ${ }^{2}$. \\ Kazuhiro Saito ${ }^{1}$
}

\section{Erratum to: Cardiovasc Intervent Radiol DOI 10.1007/s00270-017-1589-1}

The article was originally published electronically on the publisher's internet portal (currently SpringerLink) on 08 February 2017 without open access.

With the author(s)' decision to opt for Open Choice, the copyright of the article changed on 23 May 2017 to (C) The Author(s) 2017 and the article is forthwith distributed under the terms of the Creative Commons Attribution 4.0 International License. The original article was corrected.

Open Access This article is distributed under the terms of the Creative Commons Attribution 4.0 International License (http:// creativecommons.org/licenses/by/4.0/), which permits use, duplication, adaptation, distribution and reproduction in any medium or format, as long as you give appropriate credit to the original author(s) and the source, provide a link to the Creative Commons license and indicate if changes were made.
The original version of this article was revised due to a retrospective Open Access order.

The online version of the original article can be found under doi:10.1007/s00270-017-1589-1.

Daisuke Yunaiyama

yuunai1211@gmail.com

1 Department of Radiology, Tokyo Medical University, 6-7-1 Nishishinjuku, Shinjuku-ku, Tokyo, Japan

2 Department of Gastrointestinal and Pediatric Surgery, Tokyo Medical University, Tokyo, Japan 